\title{
A comparison of six models used to describe ewe growth to maturity
}

G E Pollott, G Galea

Royal Veterinary College, London, United Kingdom

Email:gpollott@rvc.ac.uk

Introduction The mature weight of breeding ewes has implications for both the amount of feed required for maintenance/productive processes as well as the likely greenhouse gas emissions, both of which are linked to bodyweight. The growth of lambs has been studied extensively (e.g. Lambe et al., 2006) but reports on ewe growth to maturity are rare. As part of a larger study into the genetics of mature weight in sheep, 4 common and 2 novel growth models were fitted to ewe weight data collected from birth to their $7^{\text {th }}$ lambing, to investigate the relationships between growth and mature weight. This paper reports on the efficacy of the models.

Materials and methods The records used in these analyses came from a fully recorded flock of 600 ewes selected for a range of objectives over an 18-year period. Animals in the flock were weighed at birth, 6 and 16 weeks of age and then annually at mating, lambing and weaning until after the $7^{\text {th }}$ lambing. Lifetime records of ewe weights were available from 1,390 ewes born over a 13-year period. A range of models were fitted to two derivatives of this dataset using the Procedure NLIN in SAS (SAS, 2003). The first dataset comprised all records available for the ewes (ALLWTS) whereas the second dataset comprised the lamb weights plus the annual mating weight (MATWTS). Six 3-parameter non-linear models were fitted to each ewe's lifetime weights; these were logistic, $3^{\text {rd }}$-order polynomial, Gompertz and Brody equations plus two new models, one based on Hill (1910) and a linear spline model with a knot and two slopes. This spline model was fitted to the data, given the birthweight and mature weight of the ewes. Because all the models had 3 parameters and the same dataset was used for all comparisons, models were compared with using the average RMS.

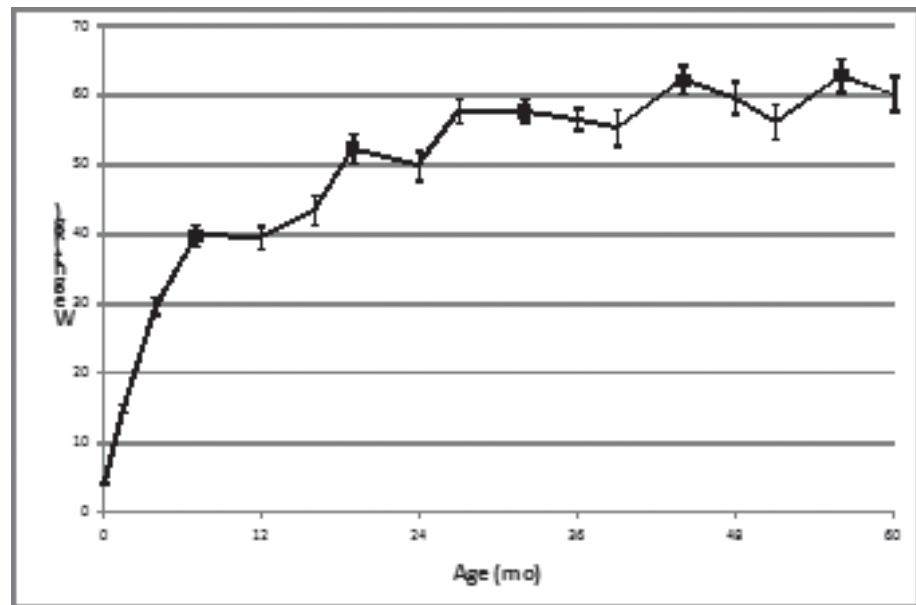

Results The growth of the ewes to maturity had a distinctive pattern (Figure) whereby growth rate up to first mating ( 7 months) had a different pattern to that between first mating and maturity. The ewes reached mature weight at 44 months of age, on average. The results of fitting the 6 models to the two datasets are summarised in Table 1. Models with a fixed rate of change (Gompertz, Brody, Logistic, Polynomial) had the largest RMS, reflecting the lack of flexibility of their parameters to deal with the two growth phases. This contrasts with the Hill curve which can change both the point of inflection and the slope of the curve and consequently had a better fit. The spline model fits two straight lines and estimates their slopes and the knot where they meet. The mean knot was at 5.08 mo and the two slopes were 228 and $23 \mathrm{~g} / \mathrm{d}$; effectively fitting one slope during early lamb growth and the second from $1^{\text {st }}$ mating to maturity. This model had the lowest RMS. The Brody model predicted the mature weight of the data most closely.

Table 1 The mean RMS and predicted mature weights from fitting 6 3-parameter growth models to ewes with all weights (ALLWTS), and lambing plus mating weights (MATWTS) (actual mean mature weights 59.8 [ALLWTS] and 62.9kg [MATWTS]).

\begin{tabular}{llllll}
\hline & $\begin{array}{l}\text { ALLWTS } \\
\text { RMS }\left(\mathrm{kg}^{2}\right)\end{array}$ & $\begin{array}{l}\text { Predicted } \\
\text { wt. }(\mathrm{kg})\end{array}$ & mature & $\begin{array}{l}\text { MATWTS } \\
\text { RMS }\left(\mathrm{kg}^{2}\right)\end{array}$ & $\begin{array}{l}\text { Predicted mature } \\
\text { wt }(\mathrm{kg})\end{array}$ \\
\hline Gompertz & $46.41^{\mathrm{a}}$ & 56.06 & 30.84 & 58.23 \\
Logistic & 51.02 & 58.63 & $38.69^{\mathrm{c}}$ & 60.27 \\
Brody & 40.25 & 59.84 & $21.71^{\mathrm{a}}$ & 62.15 \\
Hill & 36.66 & 57.87 & $19.36^{\mathrm{ab}}$ & 61.16 \\
Spline model & 27.64 & NA & $14.57^{\mathrm{b}}$ & NA \\
Polynomial & $44.63^{\mathrm{a}}$ & 57.21 & $36.81^{\mathrm{c}}$ & 60.90 \\
\hline \hline
\end{tabular}

Means within a column with the same superscript were not significantly different $(\mathrm{P}<0.05)$; means without superscripts were significantly different

Conclusions When modelling liveweight to maturity in female ewes, growth models need to cope with the effects of pregnancy and lactation on growth. Model parameters need to be flexible or designed to cope with these effects.

\section{References}

Hill, A. V. 1910. Journal of Physiology 40, iv-vii.

Lambe, N.R., Navajas, E.A, Simm, G., Bunger, L., 2006. Journal of Animal Science, 84, 2642-54.

SAS. 2004. SAS Institute. 2004. SAS Institute Inc., Cary, NC. 